\title{
Substantiation of the parameters of an innovative working body for shallow tillage
}

\author{
Galina Parkhomenko ${ }^{1, *}$, Sergey Kambulov ${ }^{1,2}$, Victor Pakhomov ${ }^{1,2}$, Vladimir Kolodkin ${ }^{2}$, \\ Viacheslav Lebedenko ${ }^{2}$, Artem Doroshenko ${ }^{2}$, Alexander Koltsov ${ }^{2}$, and Denis Muratov ${ }^{2}$ \\ ${ }^{1}$ State Scientific Establishment "Agricultural Research Center "Donskoy", 14, Lenin st., 347740, \\ Zernograd, Russia \\ ${ }^{2}$ Don State Technical University, 1, Gagarin sq., 344003, Rostov on Don, Russia
}

\begin{abstract}
The purpose of study: determine the rational parameters of an innovative working body that carries out a high-quality technological process of shallow soil cultivation. An innovative working body for shallow soil cultivation was developed on the basis of nature-like technologies that are currently relevant in scientific research. The ratio when using the golden ratio arises when comparing curvilinear and rectilinear, i.e. natural and artificial forms. The development of a new working body design is based on the physics of the interaction process with the processed environment, using analogies of shape and optimal proportions existing in nature. The working body design for shallow tillage with curved surfaces of increased streamlining using the configuration of natural sliding lines of the treated medium layer during cultivation has been developed. Depending on the required processing depth $(6-16 \mathrm{~cm})$, the innovative working body efficiently performs the cutting process with sliding, and also performs flat-cut loosening. Rational parameters and functioning modes of an innovative working body for shallow tillage have been obtained: length $-305 \mathrm{~mm}$; working width $-450 \mathrm{~mm}$; angle of crumbling, sharpening, posterior occipital cutting, mortar, rise $-15,12,10,75-110,10$ degrees respectively; speed - 9$12 \mathrm{~km} / \mathrm{h}$.
\end{abstract}

\section{Introduction}

Tillage is a very important technological process of agricultural production, aimed at obtaining crop products [1]. Soil loss in the erosion-prone regions of the European Union is $2.46 \mathrm{t} / \mathrm{ha}$ per year, resulting in a total volume of up to 970 million tons per year [2]. At the European level, many efforts have been made to promote more sustainable soil cultivation [3]. Methods for soil conservation in regions prone to erosion are being developed [4, 5]. The priority area of research is the development of designs for innovative soil protection working bodies.

The purpose of study: to determine the rational parameters of an innovative working body, carrying out a qualitative technological process of shallow tillage.

\footnotetext{
*Corresponding author parkhomenko.galya@yandex.ru
} 


\section{Materials and methods}

On the basis of theoretical and experimental studies, the working body design for shallow soil cultivation (Figure 1) with curved surfaces of increased streamlining using the configuration of natural sliding lines (least resistance) of the layer of the treated medium during cultivation has been developed.

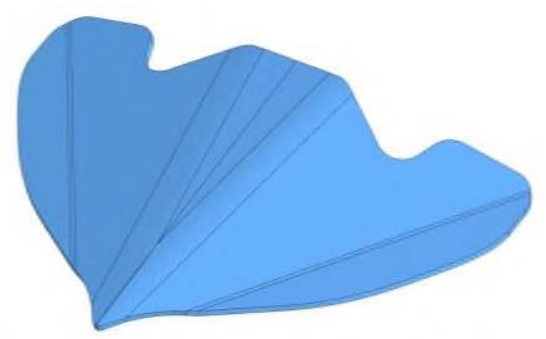

Fig. 1. General view of the innovative working body

An innovative working body for shallow soil cultivation was developed based on nature-like technologies that are currently relevant in scientific research. The methodology of nature-like technologies is based on approaching nature-like attractors based on a cenological approach, similar to biocenoses in nature. The manifestation of structural harmony and order in nature is the so-called golden ratio, the use of the principle of which in a broad sense will allow for nature-like control in the technosphere.

The ratio when using the golden ratio arises when comparing curvilinear and rectilinear, i.e. natural and artificial forms.

The development of the innovative working body design is based on the physics of the interaction process with the processed environment, using the analogies of form and optimal proportions that exist in nature [6].

When substantiating the parameters of the working body, the angle of natural displacement of the soil layer was taken into account, and the shape was chosen based on the configuration of the natural sliding lines of the soil and the trajectories of its least resistance to deformation and crumbling [7-11].

\section{Research results}

When the working body of the cultivator (Figure 2) interacts with the treated environment, the soil and weeds are affected, which can be characterized by the total concentrated load $N_{\Sigma}$, directed by normal to the cutting edge. Under the action of friction of the working body and the processed medium, a force arises $F=N_{\Sigma} \cdot \operatorname{tg} \varphi$, which is the total concentrated load $N_{\Sigma}$, applied not to the normal relative to the cutting edge of the working body, but by the angle of friction $\varphi$. Total concentrated load $N_{\Sigma}$ can be represented by two projections: in the direction of the speed of the working body translational movement $P$, deviated from the normal taking into account the opening angle $2 \cdot \gamma$ by $90-\gamma$, and tangent along the cutting edge $T$. It was found that under the condition $\frac{\pi}{2}-\gamma>\varphi$ follows $F<N_{\Sigma} \cdot \operatorname{tg}\left(\frac{\pi}{2}-\gamma\right)$, in this case, the tangential component of the total concentrated load exceeds the friction force with the medium being processed $T>F$, weeds and lumps of soil make a relative movement, moving along the cutting edge, which contributes to an 
increase in the quality of work, since crumbling of the layer is observed when interacting with the curved surface of the working body and pruning of weeds in the process of sliding cutting. In these conditions, the processed environment is influenced by the forces $P$ and $T-F$, resulting total $\Sigma$ of which is directed at an angle of friction $\varphi$ to the normal relative to the surface of the working body.

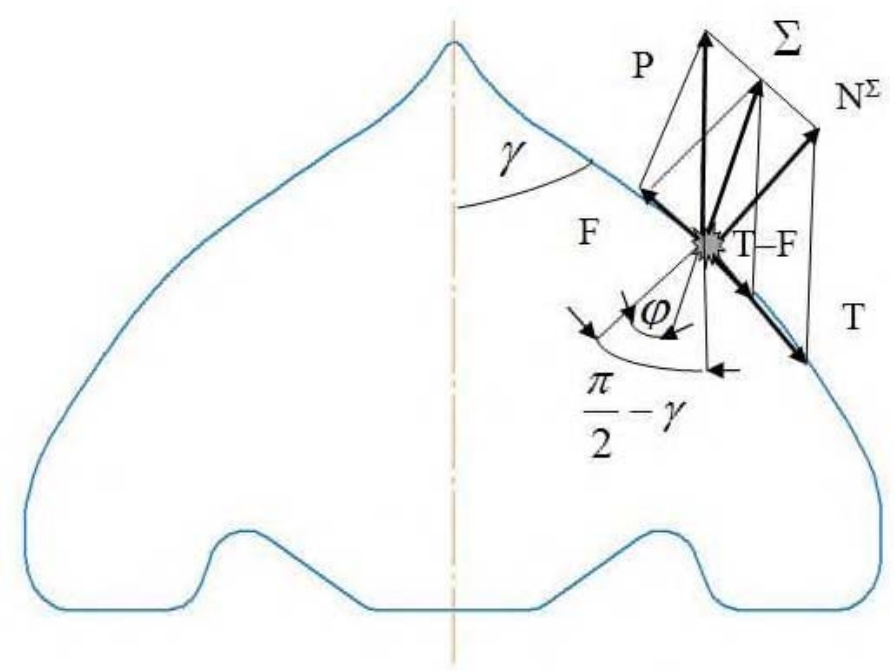

Fig. 2. Force interaction of the working body with the processed medium

With the translational movement of the working body, the layer of the treated medium moves in the direction of the resulting total force action $\Sigma$, moving directly along its surface, thus, the cutting process is accompanied by sliding. The slip coefficient increases with an increase in the fraction of the trajectory of the relative movement of the medium being treated along the working body in comparison with the absolute movement and tends to the highest in the case of a curvilinear surface. In addition to the shape, the sliding coefficient of weeds on the surface is affected by the opening angle of the working body $2 \cdot \gamma$. Thus, to ensure sliding cutting when the working body interacts with the medium being processed, it is necessary to choose the opening angle of the working body $2 \cdot \gamma$ guided by addiction:

$$
\gamma \leq \frac{\pi}{2}-\varphi
$$

To ensure a high degree of cutting of weeds and high-quality of soil crumbling, the cutting angle $\beta^{\prime}$, formed by the top chamfer of the cutting edge and the horizontal plane (Figure 3) should have the smallest value. 


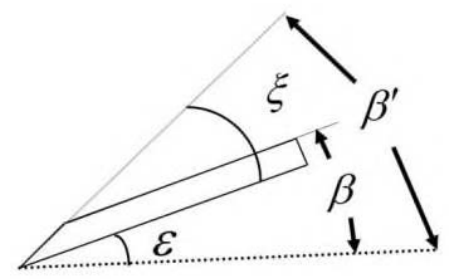

Fig. 3. Cutting and crumbling angles

However, its smallest value is limited by the taper angle $\xi$, the minimum of which is selected from the strength condition of the material used for the manufacture of the working body. In this case, the working body, like a cutter, has a gap between the horizontal and its lower surface, characterized by the posterior occipital cutting angle $\varepsilon$, the smallest value of which is also limited. Based on these restrictions, the crumbling angle is set $\beta$, which is the deviation of the upper plane of the working body from the bottom of the furrow:

$$
\beta^{\prime}=\xi+\varepsilon
$$

With the lower sharpening of the working body, the cutting and crumbling angles are equal $\beta^{\prime}=\beta$. In cases of using upper and a combination of upper and lower sharpening, the cutting angle $\beta^{\prime}$ exceeds the crumbling angle $\beta$ by the minimum value taking into account the sharpening angle $\xi$, i.e. $\beta^{\prime}>\beta$.

The role of the cultivator's working body is to ensure that the cracks formed in the soil do not comb out the root system of weeds, but cut it. For this purpose, the angle of cutting (crumbling) is performed as small as possible even for loosening working bodies. As long as the weeds are supported by the soil, they are easy to cut. If the weed plant is pulled out of the soil, then it is much more difficult to cut it. For this reason, the weed must slide along the cutting edge. When cutting with simultaneous slip along the cutting edge, the value of the cutting force will decrease with increasing trajectory of the longitudinal relative movement. This is due to the fact that when the treated medium slides along the cutting edge, tensile and shear stresses arise inside the formation, which, as you know, are characterized by lower resistance than shear deformation. The unevenness of the cutting edge captures the particles of the processed medium and displaces them. This is also due to the fact that the working body has the shape of a wedge with an angle at the top $2 \cdot \gamma$, in this case, the length of the cutting edge (especially curved) is always greater than the width of the strip processed by it. Therefore, other things being equal, the load per unit length of the cutting edge, i.e. specific cutting work will be less.

Thus, the angle of crumbling of the working body $\beta$ represents the minimum cutting angle $\beta^{\prime}$ and is determined by the expression:

$$
\beta \leq \varepsilon+\xi
$$

With the forceful interaction of the layer and the working body from the soil, there acts the reaction $Q$ of undeformed layer of the treated medium (Figure 4). 


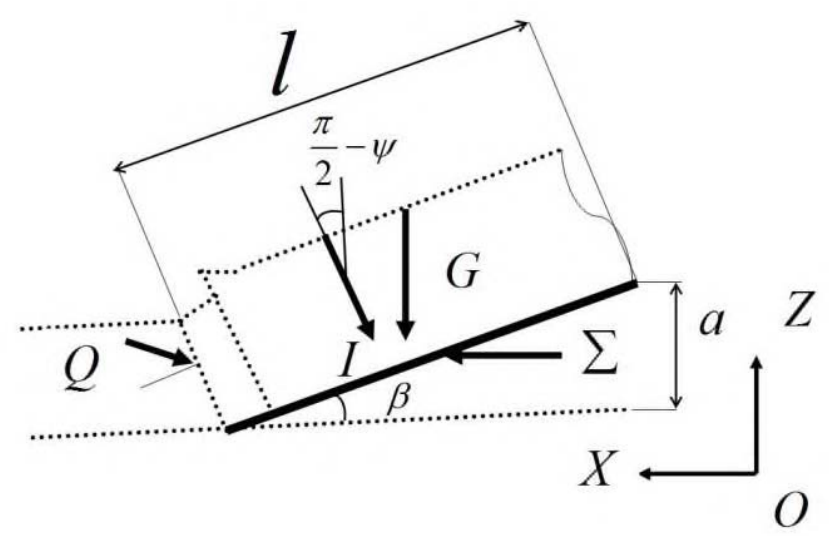

Fig. 4. Scheme of deformation of the treated medium by the working body

Besides the reaction $Q$ from the side of the soil, the gravity of the layer acts on the working body $G$; the resulting $\Sigma$ the elementary normal forces of soil resistance and friction on the surface deviating from the normal by the angle of external friction $\varphi$; the force $I$, due to the inertia of the soil layer, directed opposite to the absolute speed of movement, taking into account the shaer (cleavage) $\psi$ and forming an angle $\left(\frac{\pi}{2}-\psi\right)$ with the axis OZ. To prevent unloading of the soil in front of the working body, the backing of the layer must be sufficient:

$$
Q_{\max }=\sigma \cdot S .
$$

where $\sigma$ - resistance of the treated medium to compression, $\mathrm{Pa}$;

$S$ - cross-sectional area of the reservoir, $\mathrm{m}^{2}$.

Solving this equation for $\sigma$, we get an expression that determines the condition under which there is no unloading of the soil in front of the working body:

$$
\sigma \geq \frac{Q}{S}
$$

Define $Q$ - reaction of undeformed soil (Figure 4).

The projections of the acting forces on the axis are in the sum equal to zero:

$$
\begin{aligned}
& -Q \cdot \sin (\psi+\rho)-I \cdot \sin \left(\frac{\pi}{2}-\psi\right)+\sum \cdot \sin (\beta+\varphi)=0 . \\
& -Q \cdot \cos (\psi+\rho)-I \cdot\left(\frac{\pi}{2}-\psi\right)-G+\sum \cdot \cos (\beta+\varphi)=0 .
\end{aligned}
$$

From equation (6) find $\sum$ : 


$$
\sum=\frac{Q \cdot \sin (\psi+\rho)+I \cdot \cos \psi}{\sin (\beta+\varphi)} .
$$

Substituting the obtained expression (8) into equation (7) and performing some transformations, we obtain $Q$ :

$$
Q=\frac{I \cdot(\sin \psi-\cos \psi \cdot \operatorname{ctg}(\beta+\varphi))+G}{\cos (\psi+\rho)+\sin (\psi+\rho) \cdot \operatorname{ctg}(\beta+\varphi)} .
$$

To determine the inertia force of the formation $I$ (dynamic soil pressure on the working body) use the theorem of changing the momentum:

$$
I \cdot d t=d m \cdot\left(V-V_{0}\right)
$$

Insofar as $V_{0}=0$, then

$$
\begin{aligned}
& I \cdot d t=d m \cdot V \\
& I=\frac{d m}{d t} V \cdot \cos \psi,
\end{aligned}
$$

where $\frac{d m}{d t}$ - mass of soil per working body per unit of time, $\mathrm{kg}$.

Let us express the mass of the reservoir through its volume, then $V=$ const :

$$
\frac{d m}{d t}=v \cdot S \cdot V
$$

where $v$-volume weight (soil density), $\mathrm{kg} / \mathrm{m}^{3}$.

Then the inertial force of the formation is determined by the formula:

$$
I=v \cdot S \cdot V^{2} \cdot \cos \psi
$$

Express the gravity of the reservoir through the volume:

$$
G=m \cdot g=S \cdot l \cdot v \cdot g,
$$

where $l$ - working body length (strut outreach), m.

When substituting the obtained expressions (15) and (9) into the formula (5), the crosssectional area $S$ shrinks, that is, the process of unloading the soil does not depend on the width of the working body. After performing some transformations, we get:

$$
\sigma \geq \frac{V^{2} \cdot v \cdot \cos \psi \cdot(\sin \psi-\cos \psi \cdot \operatorname{ctg}(\beta+\varphi))+l \cdot g \cdot v}{\cos (\psi+\rho)+\sin (\psi+\rho) \cdot \operatorname{ctg}(\beta+\varphi)}
$$

Inequality (16) determines the condition under which there is no soil unloading in front 
of the working body. In the resulting expression (16) $\psi$ - shear angle (cleavage) is determined by the formula:

$$
\psi=\frac{\pi}{2}-\frac{\beta+\varphi+\rho}{2} .
$$

This equation was derived based on Mohr's theory of strength, according to which the fracture of the formation occurs in the plane, where the action of the normal and tangent creates a stress equal to the net shear, i.e. each time the shear angle is set such that the shear (cleavage) force is minimal, the value of which depends on soil moisture [12-15].

From the analysis of expression (16) it follows that the unloading of the soil in front of the working body occurs with an increase in the length of the working body, soil density, speed of the unit. Physical and mechanical properties of soil and crumbling angle affect this process, while dimensions of the cross section of seam, on contrary, do not. Thus, the improvement of the working body in terms of transformation into a curvilinear shape, which increases the perimeter of its geometric surfaces, does not violate the required parameters of the technological process with the optimally selected parameters. Using the resulting expression (16) $l$ is selected so that there is no unloading of the soil in front of the working body, i.e. the resistance to compression of the treated medium was overcome and the formation moved in the process of movement.

Working body width $b$ set for the required width of the cultivator $B$, which is selected according to the nominal tractive effort of the applied power unit.

For various layouts, the working body width $b$ (Figure 5) can be determined taking into account the overlap $\Delta$, guided by the ratio:

$$
B=b \cdot n-\Delta \cdot(n-1)
$$

where $n$ - number of working bodies.

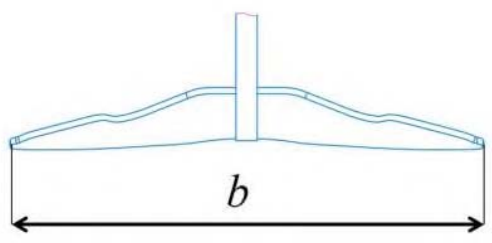

Fig. 5. Working body width

Strut height also matters for cultivators: the higher the strut, the higher the clearance, determined by the distance between the frame and the soil surface, the less likely it is that there will be clogging of crop residues. Strut height $H$ determined (Figure 6) depending on the depth of soil cultivation $a$ and the height of the working body profile projection $h$ by ratio:

$$
H \geq 2 \cdot a+h
$$

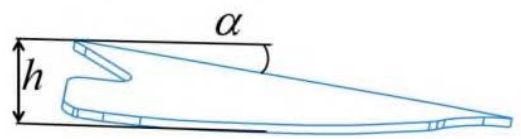


Fig. 6. Working body profile projection

Height of the working body profile projection $h$ associated with the elevation angle $\alpha$ :

$$
\operatorname{tg} \alpha=\operatorname{tg} \beta \cdot \sin \gamma
$$

Based on the obtained dependencies, parameters and modes of functioning of the working body of the cultivator, presented in Table 1, were determined.

Table 1. Parameters and modes of functioning of an innovative working body

\begin{tabular}{|c|c|c|}
\hline Indicator name & Designation, dimension & Indicator value \\
\hline Tillage depth & $a[\mathrm{~cm}]$ & $6-16$ \\
\hline Unit speed & $V[\mathrm{~km} / \mathrm{h}]$ & $9-12$ \\
\hline Crumbling angle & $\beta[$ degrees] & 15 \\
\hline Sharpening angle & $\xi[$ degrees $]$ & 12 \\
\hline Opening angle & $2 \cdot \gamma[$ degrees $]$ & $75-110$ (variable) \\
\hline Posterior occipital cutting angle & $\varepsilon[$ degrees $]$ & 10 \\
\hline Working body length & $l[\mathrm{~mm}]$ & 305 \\
\hline Working body width & $b[\mathrm{~mm}]$ & 450 \\
\hline Profile projection height & $h[\mathrm{~mm}]$ & 60 \\
\hline Elevation angle & $\alpha[$ degrees] & 10 \\
\hline
\end{tabular}

It should be noted that the opening angle of the working body is variable due to the curved shape of the cutting edge. Thus, the working body, depending on the processing depth, can qualitatively perform the cutting process with sliding, as well as carry out flatcut loosening. Flat-cut soil cultivation is carried out to a depth (up to $16 \mathrm{~cm}$ ) exceeding the depth of the occurrence of root systems' bulk of weeds. The crumbling of the layer of the treated medium by the working body occurs along the path of least resistance of the soil along the sliding lines, which have a curved shape.[16-19]

\section{Conclusion}

Research has been carried out, as a result of which the design of an innovative working body has been developed, depending on the required processing depth $(6-16 \mathrm{~cm})$, which qualitatively performs the cutting process with sliding, as well as performs flat-cutting loosening.

Rational parameters and modes of functioning of an innovative working body for shallow tillage have been obtained: length - $305 \mathrm{~mm}$; capture width $-450 \mathrm{~mm}$; the angle of crumbling, sharpening, posterior occipital cutting, mortar, lifting - 15, 12, 10, 75-110, 10 degrees respectively; speed $-9-12 \mathrm{~km} / \mathrm{h}$.

\section{References}

1. A. Mamkagh, Asian Journal of Advances in Agricultural Research, 9(1), 1-7 (2019) https://doi.org/10.9734/AJAAR/2019/46706 
2. P. Panagos, P. Borrelli, J. Poesen, C. Ballabio, E. Lugato, K. Meusburger, L. Montanarella, C. Alewel, Environmental Science \& Policy, 54, 438-447 (2015) https://doi.10.1016/j.envsci.2015.08.012

3. S. G. Parkhomenko, Environmental Engineering, 3(13), 79-86 (2019) https://doi.org/10.37700/enm.2019

4. A. Chappell, N. Webb, Aeolian Research, 23, 63-78 (2016) https://doi.org/10.1016/j.aeolia.2016.09.006

5. I. Katra, A. Gross, N. Swet, S. Tanner, H. Krasnov, A. Angert, Sci. Rep., 6, 24736 (2016) https://doi.org/10.1038/srep24736

6. B. A. Volik, A. I. Babble, A. V. Konoviy, Environmental Engineering, 2(10), 45-48 (2018) http://enm.khntusg.com.ua/index.php/enm/article/view/87

7. K. Adhikari, A. E. Hartemink, Geoderma, 262, 101-111 (2016) https://doi.org/10.1016/j.geoderma.2015.08.009

8. V. Couvreur, J. Vanderborght, X. Draye, M. Javaux, Water Resources Research 50(11), 8891-8906 (2014) https://doi.org/10.1002/2014WR015608

9. Z. Sándor; M. Tállai; I. Kincses; Z. László; J. Kátai; I. Vágó, DRC Sustainable Future 1(1), 14-20 https://doi.org/10.37281/DRCSF/1.1.3

10. G. F. Botta, D. L. Antille, F. Bienvenido, D. Rivero, E. E. Contessotto, Engineering for $\begin{array}{llll}\text { Rural Development. Jelgava, 22, 174-178 } & \text { (2019) }\end{array}$ https://doi.org/10.22616/ERDev2019.18.N216

11. M. Mairghanya, A. Yahya, N. M. Adam, A. S. Mat Su, W. Aimrun, S. Elsoragaby, Soil and Tillage Research, 194 (2019) https://doi.org/10.1016/j.still.2019.104318

12. V. R. Akuraju, D. Ryu, B. George, Y. Ryu, K. Dassanayake, Agric. For. Meteorol. 232, 489-499 (2017) https://doi.org/10.1016/j.agrformet.2016.10.007

13. Y. Fang, Y. Du, J. Wang, A. Wu, S. Qiao, B. Xu, S. Zhang, K. H. M. Siddique, Y. Chen, Front. Plant Sci. (2017) https://doi.org/10.3389/fpls.2017.00672

14. D. Helmana, I. M. Lenskya, D. J. Bonfilb, Met 232, 11-23 (2019) https://doi.org/10.1016/j.fcr.2018.12.003

15. O. Miller, D. Helman, T. Svoray, E. Morin, D. J. Bonfil, Field Crops Research, 231 (2018) https://doi.10.1016/j.fcr.2018.11.011

16. S. I. Kambulov, I. V. Bozhko, A. V. Olshevskaya, MATEC Web of Conferences, 224, 05022 (2018) https://doi.org/10.1051/matecconf/201822405022

17. I. Bozhko, G. Parkhomenko, S. Kambulov, A. Boyko, V. Kolodkin, M. Magomedov, D. Rudoy, E3S Web of Conferences, 175, 05025 (2020) INTERAGROMASH 2020 https://doi.org/10.1051/e3sconf/202017505025

18. G. Parkhomenko, I. Bozhko, S. Kambulov, A. Boyko, O. Polushkin, V. Lebedenko, A. Beskopilniy, A. Olshevskaya, E3S Web of Conferences, 175, 09006 (2020) INTERAGROMASH 2020 https://doi.org/10.1051/e3sconf/202017509006

19. V. V. Ivanov, S. I. Popov, Ju. V. Marchenko, E. V. Marchenko, N. S. Dontsov, S. A. Timofeev, Thickness of vibrational mechanochemical solid-lubricant coating in friction pairs of transport engineering products. XII International Scientific Conference on Agricultural Machinery Industry (INTERAGROMASH 2019): IOP Conference Series: Earth and Environmental Science, 403, 012115 (2019) doi:10.1088/1755-1315/403/1/012115 